This series is published by the

University of Oslo Department of Economics

P. O.Box 1095 Blindern

N-0317 OSLO Norway

Telephone: + 4722855127

Fax: $\quad+4722855035$

Internet: http://www.oekonomi.uio.no/

e-mail: $\quad$ econdep@econ.uio.no
In co-operation with

\section{The Frisch Centre for Economic Research}

\section{Gaustadalleén 21}

N-0371 OSLO Norway

Telephone: $\quad$ +4722958820

Fax: $\quad$ +4722958825

Internet: http://www.frisch.uio.no/

e-mail: $\quad$ frisch@frisch.uio.no

List of the last 10 Memoranda:

\begin{tabular}{|ll|l|}
\hline No & 12 & $\begin{array}{l}\text { Hilde C. Bjørnland and Kai Leitemo } \\
\text { Identifying the Interdependence between US Monetary Policy and the } \\
\text { Stock Market. 34 pp. }\end{array}$ \\
\hline No 11 & $\begin{array}{l}\text { Kari Due-Andresen } \\
\text { Tax evasion and labour supply in Norway in 2003: Structural models } \\
\text { versus flexible functional form models. 44 pp. }\end{array}$ \\
\hline No & 10 & $\begin{array}{l}\text { Steinar Holden and Fredrik Wulfsberg } \\
\text { Downward Nominal Wage Rigidity in the OECD. 39 pp. }\end{array}$ \\
\hline No & 09 & $\begin{array}{l}\text { Kjell Arne Brekke, Karine Nyborg and Mari Rege } \\
\text { The Fear of Exclusion: Individual Effort when Group Formation is } \\
\text { Endogenous. 23 pp. }\end{array}$ \\
\hline No & 08 & $\begin{array}{l}\text { Geir B. Asheim and Bertil Tungodden } \\
\text { A new equity condition for infinite utility streams and the possibility of } \\
\text { being Paretian. 14 pp. }\end{array}$ \\
\hline No & 07 & $\begin{array}{l}\text { Hilde Bojer } \\
\text { Income inequality and the economic position of women in Norway 1970 } \\
-2002.24 \text { pp. }\end{array}$ \\
\hline No & 06 & $\begin{array}{l}\text { Øystein Jørgensen, Tone Ognedal and Steinar Strøm } \\
\text { Labor supply when tax evasion is an option. 30 pp. }\end{array}$ \\
\hline No & 05 & $\begin{array}{l}\text { Rolf Golombek and Michael Hoel } \\
\text { The Kyoto agreement and Technology Spillovers. 22 pp. }\end{array}$ \\
\hline No & 04 & $\begin{array}{l}\text { Cathrine Hagem and Hege Westskog } \\
\text { Dominant Agent and Intertemporal Emissions Trading. 35 pp. }\end{array}$ \\
\hline No & 03 & $\begin{array}{l}\text { Halvor Mehlum and Karl Moene } \\
\text { Fighting against the odds. 18 pp. }\end{array}$ \\
\hline
\end{tabular}

A complete list of this memo-series is available in a PDF® format at: http://www.oekonomi.uio.no/memo/ 


\title{
An analytical model of required returns to equity under taxation with imperfect loss offset
}

\author{
Diderik Lund \\ Department of Economics, University of Oslo*
}

October 2003, this revision May 2005

\begin{abstract}
Lund (2002a) showed in a CAPM-type model how tax depreciation schedules affect required expected returns after taxes. Even without leverage higher tax rates implied lower betas when tax deductions were risk free. Here they are risky, and marginal investment is taxed together with inframarginal in an analytical model of decreasing returns. With imperfect loss offset tax claims are analogous to call options. The beta of equity is still decreasing in the tax rate, but increasing in the underlying volatility. The results are important if market data are used to infer required expected returns, and in discussions of tax design.

KEywords: Corporate tax, depreciation, imperfect loss offset, cost of capital, uncertainty

JEL CLASSIFICATION NUMBERS: F23, G31, H25
\end{abstract}

* Address: P.O.Box 1095, Blindern, NO-0317 Oslo, Norway, phone +47 22855129, fax +4722855035 , e-mail diderik.lund@econ.uio.no, web page http://folk.uio.no/dilund 


\section{Introduction}

This paper presents an analytical model of imperfect loss offset, values tax claims based on capital market equilibrium relationships, and explores the consequences for the systematic risk of the net after-tax cash flow of a firm. The paper extends Lund (2002a), who showed how corporate income tax rates and depreciation schedules affect the required returns to equity after corporate taxes. While it has long been recognized that corporate taxes affect the required returns to equity and debt when there is leverage, Lund (2002a) analyzed a mostly neglected effect which occurs also in a fully equity-financed firm. The intuition is that a pure cash flow tax, with payout of negative taxes, does not affect required returns, since it acts cash-flow-wise as just another shareholder. Compared with this, a depreciation schedule acts risk-wise in the opposite way of leverage, thus reducing the required expected return to equity after corporate taxes.

Most of the analysis in Lund (2002a) assumed that the tax value of future deductions, such as depreciation, is risk free. While such an assumption has been seen as a good approximation in much of the literature (e.g., Gordon and Wilson (1986), Summers (1987)), many firms are, especially in recessions, out of tax position for one or more years. Since the riskiness of the tax position is crucial for the results, the present paper sets up an analytical model of this risk. The required return is a characteristic of the marginal investment, but the tax position depends also on infra-marginal investment. Thus a simple production function with decreasing returns to scale is introduced. Results are presented both for the case when a marginal investment is taxed alone, and for the case when it is taxed together with infra-marginal investment.

Both in this and the previous paper the results are driven by the fact that future deductions are less risky than the operating cash flow of the firm. When marginal investment is taxed together with infra-marginal investment, the effect depends on the (scale) elasticity of the production function. With highly decreasing returns to scale, the approximation of risk free deductions holds very closely, and the beta of equity after a corporate income tax is almost as low as $1-t$ multiplied by the before-tax beta, where $t$ is the tax rate. A higher elasticity, closer to constant returns to scale, is equivalent to approaching a situation where 
the marginal project is taxed alone. Even in that limiting case, the after-tax beta of equity is substantially less than the before-tax beta, but the ratio of the two betas is closer to $(1-t) / 2$, not $1-t$, for typical values of other exogenous parameters. The quantitative importance of the results is, however, strengthened by the fact that the after-tax beta is a convex function of the scale elasticity. Only when this elasticity is fairly close to unity, is the after-tax beta substantially higher than its value when deductions are risk free.

Many recent studies consider the risk of each element of a cash flow separately, avoiding a characterization of the net cash flow. This raises the question whether such a characterization is interesting at all. Treating different elements separately is known in public finance from, e.g., Fane (1987) and Bond and Devereux (1995). In corporate finance it is known since Myers (1974), and this method for capital budgeting is recommended by many textbooks.

Nevertheless, most firms still apply a single risk-adjusted discount rate to their expected net after-tax cash flows, as shown in the survey by Graham and Harvey (2001). Lund (2002a) showed that this does not conform with standard theory when firms operate under more than one tax system. Furthermore, tax authorities often analyze alternative corporate tax systems using similar methods, while the discount rate should really be tax dependent and thus endogenous in such an analysis. These two practices could possibly be improved upon by considering elements of cash flows separately, and if this is implemented, the present paper merely serves to illustrate the magnitude of mistakes which have been made.

There is a third practice for which the risk of net cash flows is crucial, however, making the topic of the present paper unavoidable. It is commonly recommended in corporate finance textbooks to use observed returns to equity as the basis for calculating required expected returns in similar activities in the future. Observed returns reflect net aftercorporate-tax cash flows. In this connection it is well known that one should "unlever" observed returns if a different degree of leverage will be used in the future. ${ }^{1}$ Lund (2002a) pointed out the need to "untax" the observed returns if the future application is under a different tax system. The present paper makes this more realistic, and also shows that there may be a need to "unaverage" the returns. 
The paper is a supplement to the empirical work on estimating marginal tax rates of firms taking tax carry-forward and carry-back into consideration. Some central references are Shevlin (1990), Graham (1996), and Shanker (2000). While the empirical studies are more realistic by taking multi-period effects into account, the present model gives analytical solutions, identifying which factors are likely to have important effects.

Previous theoretical papers which observe similar effects include Levy and Arditti (1973), who observe that taxes with depreciation schedules affect the required expected rate of return after tax. Their model is an extension of Modigliani and Miller (1963), introducing depreciable assets in that model, but maintaining the assumptions of constant perpetual expected cash flows and full loss offset. Lund (2003a) discusses their model and claims that a more realistic alternative turns their results around. ${ }^{2}$

Galai (1988) (very briefly, p. 81) and Derrig (1994) both discuss the effect of a corporate income tax on the systematic risk of equity based on the CAPM. Derrig does not observe the necessity of solving for the expected rate of return of an after-tax marginal project. ${ }^{3}$

Both Levy and Arditti (1973) and Derrig (1994) consider only one simple tax system, and assume that the firm is certain to be in tax position. The present paper (like Lund (2002a)) is an extension in both respects. Galai (1988) considers both risky debt and a risky tax position. None of the previous studies consider decreasing returns to scale, i.e., an analytical model of imperfect loss offset.

Section 2 presents a two-period model in which the firm produces with decreasing returns to scale and pays taxes with certainty. Section 3 introduces uncertainty about whether taxes are paid. While these two sections focus on the after-tax cost of capital, section 4 gives results on the cost of capital before taxes. Section 5 generalizes the tax system, allowing different tax treatments of the entry cost. Section 6 contains additional discussion of some aspects of the model. Section 7 concludes. Some proofs and additional details are in the appendix. 


\section{The model when the tax position is certain}

A firm invests in period 0 and produces in period 1 , only. ${ }^{4}$ The firm considers an investment project with decreasing returns to scale. It is free to choose the scale of investment. The optimal choice is endogenous, determined by the tax system and other parameters in each case below. In this way we also characterize the minimum required expected return to equity in each case.

Assumption 1: The firm maximizes its market value according to the Capital Asset Pricing Model,

$$
E\left(r_{i}\right)=r+\beta_{i}\left[E\left(r_{m}\right)-r\right]
$$

where $r>0 . .^{5}$

When various tax systems are considered below, these are assumed not to affect the capital market equilibrium. This will be a good approximation if they apply in small sectors of the economy (e.g., natural resource extraction), or abroad in economies ("host countries") which are small in relation to the domestic one. ${ }^{6}$ This is thus a partial equilibrium analysis.

The ("home") economy where the firm's shares are traded may have a tax system, which is exogenously given in the analysis, and reflected in $r .^{7}$

A consequence of the CAPM is that the claim to any uncertain cash flow $X$, to be received in period 1 , has a period-0 value of

$$
\varphi(X)=\frac{1}{1+r}\left[E(X)-\lambda \operatorname{cov}\left(X, r_{m}\right)\right]
$$

where $\lambda=\left[E\left(r_{m}\right)-r\right] / \operatorname{var}\left(r_{m}\right)$. Equation (2) defines a valuation function $\varphi$ to be applied below.

A product price, $P$, will most likely not have an expected rate of price increase which satisfies the CAPM. ${ }^{8}$ A claim on one unit of the product will satisfy the CAPM, however, so that the beta value of $P$ should be defined in relation to the return $P / \varphi(P)$,

$$
\beta_{P}=\frac{\operatorname{cov}\left(\frac{P}{\varphi(P)}, r_{m}\right)}{\operatorname{var}\left(r_{m}\right)} .
$$

Assumption 2: In period 0 the firm invests an amount $I>0$ in a project. In period 1 the project produces a quantity $Q=f(I)=\omega I^{\alpha}$ to be sold at an uncertain price $P$. The 
production function $f$ has $\omega>0, \alpha \in(0,1)$. The joint probability distribution of $\left(P, r_{m}\right)$ is exogenous to the firm, and $\operatorname{cov}\left(P, r_{m}\right)>0$. There is no production flexibility; $Q$ is fixed after the project has been initiated.

The assumption of $\operatorname{cov}\left(P, r_{m}\right)>0$ can easily be relaxed. It is only a convenience in order to simplify the verbal discussions below.

Assumption 3: An entry cost $M_{0}$ is paid for the right to undertake the investment project. This is competitively determined among firms with the same tax position (see Assumption 4), so that the net value after taxes to the firm of paying this entry cost, undertaking the project in optimal scale, and paying taxes, is zero. The sequence of events in period 0 is as follows: (a) The authorities determine the tax system for both periods. (b) The firm pays the entry cost $M_{0}$. (c) The firm determines how much to invest, $I$.

The entry cost seems to be the most satisfactory way to include decreasing returns to scale in an equilibrium model. The entry cost could be an R\& D expenditure, a patent or license, an investment in a plant, or something else. Without this cost, pure profits would be freely available, which is not an equilibrium situation. However, under Assumption 3 there is no economic difference between the two costs, $M_{0}$ and $I$. Only their sum matters to the firm, and the produced quantity might as well have been written as a function of their sum, $M_{0}+I$. With no difference between the two, the model would fail to capture the idea of imperfect loss offset under decreasing returns, i.e., with the marginal investment project being taxed together with inframarginal investment.

In order to let the model have this feature, while at the same time including the entry cost and thus the equilibrium character of the model, a difference is introduced in the tax treatment of the two costs. The entry cost could be immediately deductible, deductible in the production period, not deductible at all, or some combination of these. Assumption 4 implies an immediate deduction. Section 5 considers a more general formulation.

Assumption 4: $A$ tax at rate $t \in[0,1)$ will be paid with certainty in the production period. The tax base is operating revenue less $c I$. There is also a tax relief of $t\left(M_{0}+a I\right)$ in period 0 . The constants $a$ and $c$ are in the interval $[0,1]$; moreover, $t[a+c /(1+r)]<1$. 
This general formulation allows for accelerated depreciation with, e.g., $a>0$ and $a+c=1$, or a standard depreciation interpreted (since there is only one period with production) as $a=0, c=1$. The requirement $t[a+c /(1+r)]<1$ precludes "gold plating incentives," i.e., the tax system carrying more, in present value terms, than one hundred percent of an investment cost. ${ }^{9}$

Assumption 4 implies that a negative tax base gives a negative tax paid out by the authorities. While this is unrealistic for most tax systems when the project stands alone, it is not at all unrealistic when the marginal project is added to other activity which is more profitable. An alternative assumption for the second period is considered in section 3 . For the first period, however, no alternative is considered. This could rely on an assumption that firms only start projects in periods in which they are in tax position to benefit immediately from deductions allowed in the first period. This does not explain how most firms get started in the first place.

The points to be made in this paper do not rely on debt financing. For simplicity it is therefore assumed that the firm is one hundred percent equity financed. If debt is introduced, as in Lund (2002a), it is clear that the analysis is mainly relevant to characterize the return on equity, explaining the title of the paper. ${ }^{10}$

\subsection{Case F: Tax deductions are risk free}

This first case ( $\mathrm{F}$ for risk Free deductions) is considered to demonstrate as simply as possible the method used in Lund (2002a), applied both to the problem solved there and to the case with decreasing returns to scale. This will show the distinction between two concepts, marginal beta and average beta, which is important when $t>0$.

In the case FC (C for CRS) of a marginal project alone, considered in Lund (2002a), the cash flow to equity in period 1 is

$$
X_{F C}=P Q(1-t)+t c I,
$$

where $Q$ in the CRS model replaces $f(I)$ in the DRS model. For each set of tax and other parameters, $Q$ is set so that the project is exactly marginal. The market value of a claim 
to this is

$$
\varphi\left(X_{F C}\right)=\varphi(P) Q(1-t)+\frac{t c I}{1+r} .
$$

For a marginal project the expression must be equal to the financing need after borrowing and taxes, $I(1-t a)$, so that $Q$ is determined by

$$
I(1-t a)=\varphi\left(X_{F C}\right)=\varphi(P) Q(1-t)+\frac{t c I}{1+r}
$$

which implies

$$
\frac{\varphi(P) Q}{I}=\frac{1-t a-t \frac{c}{1+r}}{1-t}
$$

The beta value of equity is a value-weighted average of the beta values of the elements of the cash flow. From (4) this is

$$
\beta_{F C}=\frac{\varphi(P) Q(1-t)}{\varphi\left(X_{F C}\right)} \beta_{P}=\frac{1-t a-t \frac{c}{1+r}}{1-t a} \beta_{P},
$$

cf. Lund (2002a), eq. (9) and (12). The main conclusion in that paper is that due to the tax depreciation schedule, the beta of equity is decreasing in the tax rate under a corporate income tax. Under a pure cash flow tax there is no such effect of the tax rate.

The intuition behind the tax effect is as follows: A pure cash flow tax $(a=1, c=0)$ does not affect the beta of equity. As compared with a cash flow tax, the typical corporate income tax postpones some deductions in the form of a tax depreciation schedule, and these will be less risky at the margin than the future operating income. Risk-wise this postponement is similar to a loan from the firm to the authorities, and thus it has the opposite effect of leverage: It reduces the systematic risk of equity.

One main assumption in this and what follows is that the underlying systematic risk, $\beta_{P}$, is unaffected by changes in the tax system. This follows from the partial-equilibrium assumption made in relation to the capital market, Assumption 1.

Consider now the DRS case, FD. Instead of technically adjusting $Q$ to find the characteristics of a marginal project, there is now a first-order condition which determines $I$, and one can then solve for the entry cost which makes the overall addition to net value equal to zero.

The cash flow to equity in period 1 is

$$
X_{F D}=P f(I)(1-t)+t c I,
$$


The market value of a claim to this is

$$
\varphi\left(X_{F D}\right)=\varphi(P) f(I)(1-t)+\frac{t c I}{1+r} .
$$

The firm chooses the optimal scale in order to maximize $\pi_{1 D}(I)=\varphi\left(X_{F D}\right)-I(1-t a)$. The first-order condition for a maximum is

$$
\varphi(P) f^{\prime}(I)=\frac{1-t a-t \frac{c}{1+r}}{1-t}
$$

The entry cost will be set so that $M_{0}(1-t) \equiv M=\pi_{1 D}(I)=\varphi\left(X_{F D}\right)-I(1-t a)$ (defining $M$ ), which implies that the total payment in period 0 is

$$
M+I(1-t a)=\varphi\left(X_{F D}\right)
$$

The beta value of equity is a value-weighted average of the beta values of the elements of the cash flow. From (9) this is

$$
\beta_{F D}=\frac{\varphi(P) f(I)(1-t)}{\varphi\left(X_{F D}\right)} \beta_{P}
$$

The parameterized production function together with the first order condition (11) gives

$$
\beta_{F D}=\frac{1-t a-t \frac{c}{1+r}}{1-t a-t \frac{c}{1+r}(1-\alpha)} \beta_{P},
$$

which again is decreasing in the tax rate as long as $c>0$. As $\alpha$ approaches unity (i.e., CRS), $\beta_{F D}$ approaches $\beta_{F C}$ (and equilibrium $M$ approaches zero).

Observe that $\beta_{F C}<\beta_{F D}$ when $t c(1-\alpha)>0$. The two different expressions for the beta of equity will be called marginal beta and average beta, respectively. They are both relevant as descriptions of systematic risk within the same project. The average beta will describe the systematic risk of the project as a whole, and in particular, the systematic risk of the shares in a firm with only this project. The marginal beta is still the relevant one for decision making at the margin, which may be decentralized within the firm. After the cost $M_{0}$ has been sunk, the correct beta for calculating the required expected rate of return is the marginal beta.

The expressions for the two betas will be somewhat more complicated in the cases which follow, in particular when the tax position is uncertain. But the difference will reappear. 
So far we can observe that the origin of the difference is the tax depreciation schedule. Only if $t c>0$, will the difference depend on $\alpha$.

There is no fundamental distinction between $M_{0}$ and $I$ from the firm's point of view. They are both paid in the same period, and the output next period, $Q$, could have been written as a function of their sum. Both betas are equal to $\beta_{P}$ if the tax rate is zero, but also if the tax rate is positive while $c$ is zero. In the present model with a sunk cost and DRS thereafter, it is the difference in tax treatment of these costs which creates the two different betas of equity. This will also be the case below when the tax position is uncertain.

When capital budgeting is presented in standard textbooks, this distinction between marginal and average beta is not mentioned. There may be good reasons for this: There are many details of projects and tax systems which have to be left out in a textbook. Lund (2002a, 2003a) emphasizes the importance of tax systems for after-tax required expected rates of return. If firms continue to rely mainly on one such required rate for their net after-tax cash flow, they should be aware of tax effects, and not only on the value of debt, which has been the traditional focus. If they want to infer the requirement from capital market data for their own shares, they should be aware that these data (if the model is true) reflect average beta, not marginal beta. In addition to the need to "unlever" and "untax" betas, there is now a need to "unaverage" betas.

\section{Case R: Uncertain tax position}

The results for case $\mathrm{F}$ above are based on the assumption that the firm is certain to be in tax position in period 1 . While the tax element $t P Q$ is perfectly correlated with the operating revenue, the depreciation deductions were assumed to be risk free, relying on the firm being in a certain tax position.

Most corporate income taxes have imperfect loss offset. If the tax base is negative one year, there is no immediate refund. The loss may under many systems be carried back and/or forward, but there are usually limitations to this, and the present value is not maintained. In a two-period model a realistic multi-period loss carry-back or carry-forward 
cannot be represented in detail. An extreme assumption which may be useful as a starting point, and which is meaningful if the two-period model is taken literally and the tax code does not allow carry-backs, is that in these cases, there is no loss offset at all. One purpose of the present paper is to see whether the results of case F vanish when deductions are risky. Thus it is relevant to consider this most extreme riskiness. The cash flow to equity in period 1 is then

$$
P Q-B(1+r)-t \chi(P Q-g B r-c I)
$$

where $\chi$ is an indicator variable, $\chi=1$ when the firm is in tax position in period $1, \chi=0$ if not.

Lund (2002a) arrived at an analytical solution for marginal beta in this case under the assumption that the marginal investment constitutes the whole tax base for the firm. ${ }^{11}$ Option valuation techniques were used to find a formula for the value of the uncertain cash flow in period 1, following Ball and Bowers (1983) and Green and Talmor (1985).

A marginal beta may now take different meanings. A more realistic marginal beta recognizes that the marginal project is part of a larger activity, and that the probability of being in tax position depends on the outcome of that larger activity. This will be analyzed in line with the model of the previous section: The larger activity consists of a DRS investment project, the output of which is being sold at a single stochastic price in the single future period. An even more realistic model would include more stochastic variables (not perfectly correlated) and/or more periods.

Let case $\mathrm{R}$ (for Risky deductions) denote the case with an uncertain tax position. The following assumption replaces Assumption 4 above:

Assumption 5: The tax base in period 1 is operating revenue less $c I$. When this is positive, there is a tax paid at a rate $t$. When it is negative, the tax system gives no loss offset at all. There is also a tax relief of $t\left(M_{0}+a I\right)$ in period 0 . We have $c \in(0,1]$, $a \in[0,1]$, and $t[a+c /(1+r)]<1$.

To have $c$ strictly positive is necessary to obtain true uncertainty about the tax position (as long as $\operatorname{Pr}(P Q>0)=1$ ), and for some of the formulae below to hold. The valuation of the non-linear cash flow is specified as follows: 
Assumption 6: A claim to a period-1 cash flow $\max (0, P-K)$, where $K$ is any positive constant, has a period-0 market value according to the model in McDonald and Siegel (1984). The value can be written as

$$
\varphi(P) N\left(z_{1}\right)-\frac{K}{1+r} N\left(z_{2}\right)
$$

where

$$
z_{1}=\frac{\ln (\varphi(P))-\ln (K /(1+r))}{\sigma}+\sigma / 2, \quad z_{2}=z_{1}-\sigma,
$$

$N$ is the standard normal distribution function, and $\sigma$ is the instantaneous standard deviation of the price.

In what follows it is assumed that the exogenous variables $\beta_{P}$ and $\sigma$ can be seen as unrelated as long as $\sigma>0$, cf. footnote 14 in McDonald and Siegel (1986). A change in $\sigma$ could be interpreted as, e.g., additive or multiplicative noise in $P$, stochastically independent of the previous $\left(P, r_{m}\right) .{ }^{12}$

It is shown in the appendix that the marginal beta is

$$
\beta_{R M}=\frac{1-t a-t N\left(z_{2 D}\right) \frac{c}{1+r}}{1-t a} \beta_{P}
$$

where $z_{2 D}$ is given by

$$
z_{2 D}=\frac{1}{\sigma}\left[\ln \left(1-t a-t N\left(z_{2 D}\right) \frac{c}{1+r}\right)-\ln \left(1-t N\left(z_{2 D}+\sigma\right)\right)-\ln \left(\frac{c}{1+r}\right)-\ln (\alpha)\right]-\frac{\sigma}{2} .
$$

Although this equation cannot be solved explicitly, it determines (one or more values for) $z_{2 D}$ implicitly ${ }^{13}$ as function(s) of $t, a, c /(1+r), \sigma$, and $\alpha$.

Furthermore it is shown that the average beta is

$$
\beta_{R A}=\frac{1-t a-t N\left(z_{2 D}\right) \frac{c}{1+r}}{1-t a-t N\left(z_{2 D}\right) \frac{c}{1+r}(1-\alpha)} \beta_{P} .
$$

This means that the relationship between marginal and average beta is just as in the previous case, which had full certainty about the tax position. There is an extra term containing $t c(1-\alpha)$ subtracted in the denominator.

The two equations (18) and (20) should be compared with (8) and (14). Clearly the effect of the uncertainty in the tax position is similar to a reduced tax rate in period 1 , 
reflecting that the probability of receiving the tax deductions is less than one hundred percent.

For comparison, the marginal beta in the stand-alone CRS case can be found by solving for $z_{2 C}$ from the following equation, also shown in the appendix,

$$
z_{2 C}=\frac{1}{\sigma}\left[\ln \left(1-t a-t N\left(z_{2 C}\right) \frac{c}{1+r}\right)-\ln \left(1-t N\left(z_{2 C}+\sigma\right)\right)-\ln \left(\frac{c}{1+r}\right)\right]-\frac{\sigma}{2},
$$

which is the limit of (19) as $\alpha \rightarrow 1$. This subcase yields,

$$
\beta_{R C}=\left(1-t N\left(z_{2 C}\right) \frac{c}{(1-t a)(1+r)}\right) \beta_{P}
$$

This is the case considered in Lund (2002a), except that equation (21) was not given there. Table 1 summarizes the five subcases considered. The rightmost column gives the ratio of $\beta_{i}$ (the beta of the cash flow to equity) to $\beta_{P}$ in each subcase $i$.

TABLE

To find the derivatives of the betas with respect to $t, a, c /(1+r), \sigma, \alpha$, one can use 1 implicit differentiation of $z_{2 D}$ as given in (19). This is done in the appendix for the HERE. case $a=0$. In order to determine the signs of the derivatives, some restrictions on the parameters are assumed. One basic restriction, cf. footnote 9, is

Assumption 7: The deductions following a unit investment cost are less than unity in present value terms: $a+c /(1+r)<1$.

It is then found that $\beta_{R A}$ is increasing in $\sigma$, decreasing in $t$, while it may be increasing or decreasing in $\alpha$, depending on parameters.

A further investigation has been done through numerical solutions of non-linear equations. The purpose of the investigation has been to trace out how the marginal and average betas depend on $t, \sigma$, and $\alpha$.

The numerical investigation has only considered cases with $a$ set to zero, and the ratio $c /(1+r)$ fixed at $1 / 1.05$. The central parameter configuration considered is $t=0.3, \sigma=0.3$. These are not unreasonable numbers (when the time unit is one year). For simplicity the verbal discussion below will assume $\beta_{P}=1$. The five equity betas for the cases with no borrowing, divided by $\beta_{P}$, are shown in Figure 1 as functions of the scale elasticity $\alpha .{ }^{14} \mathrm{~A}$ sixth relevant curve for comparison would be $\beta_{P}$ itself, horizontal at 1.0 in the diagram. This would be the beta of equity without taxation or with true cash flow taxation. 
Figure 1 shows that the betas have the expected properties. The two dotted curves show the marginal $\beta$ when the value of tax deductions is risk free, $\beta_{F C}$, and also when a marginal project stands alone with risky deductions (no loss offset), $\beta_{R C}$. These do not depend upon the scale elasticity, $\alpha$. They are both substantially lower than $\beta_{P}$, but the uncertainty of the tax position increases marginal $\beta$ from 72 percent to 83 percent. This reflects that the depreciation schedule reduces the systematic risk of equity, and that the uncertain tax position counteracts this to some extent, but not completely.

The two dashed curves show two DRS cases, the average $\beta$ when deductions are risk free, $\beta_{F D}$, and the marginal when they are risky, $\beta_{R M}$. The former falls from unity to $\beta_{F C}$ as $\alpha$ is increased. This simply reflects the difference in tax treatment of $M_{0}$ and $I$, and the fact that $M_{0}$ becomes relatively smaller as $\alpha \rightarrow 1^{-}$. $\beta_{R M}$, however, rises from $\beta_{F C}$ to $\beta_{R C}$ as $\alpha$ is increased. This follows from the increased probability of being out of tax position. When $\alpha$ is low enough, the tax position is virtually certain, and the marginal $\beta$ under DRS is not different from that under CRS and a certain tax position. But as $\alpha$ increases, so does the uncertainty about the tax position, and as $\alpha \rightarrow 1^{-}$, there is no gain anymore for the marginal project of being taxed together with a DRS project. It approaches the case where the marginal project is taxed alone.

The solid curve shows the average $\beta_{R A}$ in the DRS case with uncertain tax position. For low $\alpha$ values, the tax position is virtually certain, so there is no discernible difference from $\beta_{F D}$ of the case of risk free deductions. Then as $\alpha$ exceeds (about) 0.5 , the effect of the uncertain tax position is that $\beta_{R A}$ takes on higher values than $\beta_{F D}$, while still being decreasing in $\alpha$. For even higher $\alpha$ values, however, the curve becomes increasing, as it approaches $\beta_{R M}$, which is increasing. This possibility is also seen from the discussion of equation (A24) in the appendix.

Clearly, even the DRS case with risky deductions can have betas substantially lower than $\beta_{P}$. In this case the marginal beta curve, $\beta_{R M}$, satisfies the intuition that it has less risk than the stand-alone marginal beta, $\beta_{R C}$, as an effect of being taxed together with an infra-marginal cash flow. But the average beta, $\beta_{R A}$, does not exhibit this property uniformly, and in fact, the difference between marginal and average beta is just as large in this case as in the case with risk free deductions if only $\alpha$ is low enough. 
Figures 2 and 3 show some sensitivities to changes in the tax rate, $t$, and the volatility, $\sigma$. The three non-constant curves from Figure 1 are reproduced as (similarly) dotted curves, and the corresponding three curves for the new value of $t$ or $\sigma$ are drawn as dashed or solid. The values of the constant $\beta_{F C}$ and $\beta_{R C}$ are now only shown implicitly, as the endpoint values for the curves. ${ }^{15}$

Figure 2 shows that all betas are increased if the tax rate is lowered (and vice versa), which was also the main point in Lund (2002a) for the cases considered there. The effect on the lowest values $\left(\beta_{F C}\right.$, which is the limit of $\beta_{R M}$ for low $\alpha$, and of $\beta_{F D}$ for high $\left.\alpha\right) 2$ seems to be proportional to $(1-t)$, which is almost correct when $c /(1+r)$ is close to unity, HERE. cf. equation (8), see also Corollary 2.2 in Lund (2002a). But the higher beta values do not change as much in absolute terms. ${ }^{16}$

Figure 3 shows only one $\beta_{F D}$ curve, as this is unaffected by a change in volatility. The figure shows that except for this, a lower $\sigma$ works in the same direction as a higher $t$. But 3 the effects of changes in $\sigma$ are only discernible for higher values of $\alpha$, and the magnitudes HERE. of the effects are not very large.

\section{Cost of capital before taxes}

In the previous two sections the effects of the tax system on the beta of equity were analyzed. Via the CAPM equation, (1), this also gives the effects on the cost of equity after corporate taxes, which is reflected in the stock market (but observe the distinction between marginal and average beta).

The cost of capital before corporate taxes, on the other hand, is the traditional measure for the effects of the tax system on the acceptance or rejection of real (non-financial) investment projects. This determines the possible distortionary effects of the tax system, although the present paper does not discuss what would be the relevant basis for comparison in various circumstances. Implicitly the comparison is with a situation without corporate taxation. Also, as stated in the introduction, no general equilibrium effects are considered.

The cost of capital for investment decisions relates to marginal profitability, so the return should be seen in relation to the investment cost $I$, neglecting the entry cost $M_{0}$. 
The expected rate of return before corporate taxes, plus 1 , is $E(P) Q / I$, which can be rewritten as

$$
\frac{E(P) Q}{I}=\frac{E(P)}{\varphi(P)} \cdot \frac{\varphi(P) Q}{I}
$$

Of the two fractions on the right hand side, the first is assumed to be exogenous, and is given by (1) and (3). The second is determined by the requirement under CRS that the project should be marginal after tax, or, under DRS, that its scale should be optimal after tax. For case F above, these requirements are given by (7) and (11), which means that one plus the required expected rate of return before corporate taxes is

$$
\frac{E(P)}{\varphi(P)} \cdot \frac{1-t a-t \frac{c}{1+r}}{1-t}
$$

cf. Hall and Jorgenson (1969), p. 395. The distortion in "one plus the expected rate of return" is the second fraction, which is independent of (total and systematic) risk, only a function of tax parameters and the risk free interest rate. The distortion is decreasing in $a$ and $c /(1+r)$. Under Assumption 7 it is increasing in the tax rate.

For case $\mathrm{R}$ with an uncertain tax position, the relevant first-order condition is given in equation (A6) in the appendix. One plus the required expected rate of return is

$$
\frac{E(P)}{\varphi(P)} \cdot \frac{1-t a-t N\left(z_{2 D}\right) \frac{c}{1+r}}{1-t N\left(z_{1 D}\right)} .
$$

Again the distortion is independent of systematic risk, but now it depends on total risk through the $N(\cdot)$ expressions.

In the appendix it is shown that when $a=0$, the endogenous part of expression (25), the second fraction, is increasing in $\alpha$ and $\sigma$. A higher $\alpha$ reduces the probability of being in tax position, and thus the expected value of depreciation deductions. This increases distortions. A higher $\sigma$ has a similar effect, and works additionally by increasing the option value of the authorities' tax claim (i.e., it enhances the effect of the asymmetry), increasing distortions. Furthermore, the distortion goes up if $t$ goes up, and likewise if $c$ goes down, as the direct effects known from (24) are dominating. These results on the cost of capital before taxes should be useful. However, they only formalize what is (more or less) known from before, whereas the results on the cost of capital after taxes are more important as corrections of current knowledge and practice. 


\section{Tax deduction for entry costs}

In addition to the tax deductions $a I$ in period 0 and $c I$ in period 1 , assume now that there are deductions $b M_{0}$ in period 0 and $h M_{0}$ in period 1 , where $b$ and $h$ are constants in the interval $[0,1]$. The extension of case $R$ will be developed, while the similar extension of case $\mathrm{F}$ can be found by setting the probabilities (the $N(\cdot)$ expressions) equal to unity.

In order to distinguish the expressions from those above, this will be called case $\mathrm{G}$ (for Generalized tax system). The cash flow to equity in period 1 is

$$
X_{G D}=\operatorname{Pf}(I)-t \cdot \max \left(\operatorname{Pf}(I)-c I-h M_{0}, 0\right) .
$$

The valuation, as of one period earlier, of a claim to this is

$$
\varphi\left(X_{G D}\right)=\varphi(P) f(I)-t\left[\varphi(P) f(I) N\left(z_{1 G D}\right)-\frac{c I+h M_{0}}{1+r} N\left(z_{2 G D}\right)\right]
$$

where

$$
z_{1 G D}=\frac{\ln (\varphi(P) f(I))-\ln \left(\frac{c I+h M_{0}}{1+r}\right)}{\sigma}+\frac{\sigma}{2},
$$

and

$$
z_{2 G D}=z_{1 G D}-\sigma
$$

Again, the expression in square brackets in (27) can be rewritten in terms of the standard Black and Scholes' formula for option pricing as $C\left(\varphi(P) f(I), c I+h M_{0}, 1, r, \sigma\right)$, i.e.,

$$
\varphi\left(X_{G D}\right)=\varphi(P) f(I)-t C\left(\varphi(P) f(I), c I+h M_{0}, 1, r, \sigma\right) .
$$

The firm chooses $I$ to maximize $\pi_{G D}(I) \equiv \varphi\left(X_{G D}\right)-I(1-t a)$. From the first-order condition follows

$$
\varphi(P) f(I)\left(1-t N\left(z_{1 G D}\right)\right)=\frac{f(I)\left(1-t a-\frac{t c}{1+r} N\left(z_{2 G D}\right)\right)}{f^{\prime}(I)} .
$$

Introducing the constant-elasticity production function gives

$$
\varphi(P) f(I)\left(1-t N\left(z_{1 G D}\right)\right)=\frac{I}{\alpha}\left(1-t a-\frac{t c}{1+r} N\left(z_{2 G D}\right)\right) .
$$

Equilibrium $M_{0}$ is given by

$$
M_{0}(1-t b)=\varphi\left(X_{G D}\right)-I(1-t a)
$$




$$
=\frac{I}{\alpha}\left(1-t a-\frac{t c}{1+r} N\left(z_{2 G D}\right)\right)+\frac{t c I N\left(z_{2 G D}\right)}{1+r}-I(1-t a)+\frac{t h M_{0} N\left(z_{2 G D}\right)}{1+r},
$$

which can be solved for

$$
M_{0}=I \frac{(1-\alpha)\left[1-t\left(a+\frac{c N\left(z_{2 G D}\right)}{1+r}\right)\right]}{\alpha\left[1-t\left(b+\frac{h N\left(z_{2 G D}\right)}{1+r}\right)\right]} .
$$

The ratio of the expressions in square brackets in the numerator and the denominator contains the effect of the different tax treatment (if any) of $I$ and $M_{0}$, respectively, in risk-adjusted expected present value terms.

We can now solve for $\varphi\left(X_{G D}\right)=$

$$
\frac{I}{\alpha}\left[1-t a-\frac{t c N\left(z_{2 G D}\right)}{1+r}(1-\alpha)+\frac{t h N\left(z_{2 G D}\right)}{1+r} \cdot \frac{(1-\alpha)\left[1-t\left(a+\frac{c N\left(z_{2 G D}\right)}{1+r}\right)\right]}{\left[1-t\left(b+\frac{h N\left(z_{2 G D}\right)}{1+r}\right)\right]}\right] .
$$

This gives the average beta for this case,

$$
\beta_{G D}=\frac{1-t a-\frac{t c N\left(z_{2 G D}\right)}{1+r}}{1-t a-\frac{t c N\left(z_{2 G D}\right)}{1+r}(1-\alpha)+\frac{t h N\left(z_{2 G D}\right)}{1+r} \cdot \frac{(1-\alpha)\left[1-t\left(a+\frac{c N\left(z_{2 G D}\right)}{1+r}\right)\right]}{\left[1-t\left(b+\frac{h N\left(z_{2 G D}\right)}{1+r}\right)\right]}} \beta_{P}
$$

Furthermore, we can express $z_{2 G D}$ (and thus also $z_{1 G D}=z_{2 G D}+\sigma$ ) in terms of the exogenous parameters implicitly through $z_{2 G D}=$

$\frac{1}{\sigma}\left[\ln \left(\frac{1-t a-\frac{t N\left(z_{2 G D}\right) c}{1+r}}{1-t N\left(z_{2 G D}+\sigma\right)}(1+r)\right)-\ln \left(c+h \frac{(1-\alpha)\left[1-t\left(a+\frac{c N\left(z_{2 G D}\right)}{1+r}\right)\right]}{\alpha\left[1-t\left(b+\frac{h N\left(z_{2 G D}\right)}{1+r}\right)\right]}\right)-\ln (\alpha)\right]-\frac{\sigma}{2}$.

While this general formulation is not immediately transparent, there are some interesting special cases. Assumption 4 gave the case of $b=1, h=0$, and was analyzed in section 3 .

Consider the case where the two costs in period $0, M_{0}$ and $I$, are treated equally by the tax system. This amounts to $a=b$ and $c=h$. It can be shown that this makes $\alpha$ vanish from both (36) and (37), so that $z_{2 G D}=z_{2 C}$, and $\beta_{G D}=\beta_{R C}$, found in (22). When the two costs are treated equally, the firm's whole activity can be seen as a marginal investment project. In relation to the issues analyzed in this paper, there is nothing which distinguishes this from a case of constant returns to scale, except that the scale of production is determined. 
Even without specifying $b$, it turns out that $h=0$ is an interesting special case. The fraction

$$
\frac{(1-\alpha)\left[1-t\left(a+\frac{c N\left(z_{2 G D}\right)}{1+r}\right)\right]}{\left[1-t\left(b+\frac{h N\left(z_{2 G D}\right)}{1+r}\right)\right]},
$$

which appears in both (36) and (37), vanishes, since it is multiplied by $h$. We find $z_{2 G D}=$ $z_{2 D}$ (of equation (19)), and $\beta_{G D}=\beta_{R A}$ (of equation (20)). This means that $b$ does not matter for the results when $h=0$, which is due to the fact that the equilibrium $M_{0}(1-t b)$ is determined endogenously. A higher (lower) $b$ will lead to a higher (lower) $M_{0}$, keeping equilibrium $M_{0}(1-t b)$ unaffected, and when $h=0$, only $M_{0}(1-t b)$ matters, not $M_{0}$ itself. For instance, the two subcases $(b=0, h=0)$ and $(b=1, h=0)$ give the same beta of equity, $\beta_{R A}$, despite the very different tax treatment of $M_{0}$.

In relation to the issues analyzed, the equality of tax treatment, $a=b$ and $c=h$, is an extreme case. While many other configurations of $a, b, c$, and $h$ are possible, case $\mathrm{R}$ above covers at least two interesting possibilities, that the entry cost is immediately deductible, and that it is not deductible at all.

\section{Discussion}

The distinction between an average and a marginal beta is one of the novelties of this paper. It has been shown that this distinction should be made even if the firm pays taxes at the margin with full certainty, given that the tax system treats the fixed cost $M_{0}$ and the variable cost $I$ differently. Since uncertainty in the model originates from only one project-related stochastic variable, and since the project without tax has no option(-like) characteristics, there is no difference between marginal and average beta if there are no taxes. But with taxes this distinction appears, even in the simplest case with full certainty about the tax position, if there are decreasing returns to scale.

Whether the distinction between marginal and average beta is important in practice, is another question. Most firms may be happy with a rough estimate of the firm's systematic risk, and may not worry too much about the details determining the required expected rate of return. Since different projects have different risk characteristics in practice, it is impossible to come up with an exact number to be used for a new project. Nevertheless the 
mechanisms described here should be known by the practitioners, who may then evaluate if, when, and how to take them into account. A thirty percent reduction in beta is hardly negligible.

A seemingly critical assumption in the paper is Assumption 6 on option-like valuation of non-linear cash flows. The underlying assumptions were not detailed, since they are well known. It should be observed, however, that the approach is more general than it seems. It is not necessary to rely on the geometric Brownian motion which is the basis for the standard option valuation theory. Any price process which does not allow arbitrage opportunities will do. But the exact solutions will of course be different with different price processes.

Likewise, Assumption 1 on the CAPM can be relaxed. The crucial assumption is the linear risk measure, which could even be related to more than one factor.

There are of course several limitations of the analysis. The uncertainty is multiplicative, which may not be necessary for the model to work (cf. Lund (2003a)), but for the simplicity of the results, in particular in the case of risky deductions. The source of uncertainty is a single stochastic variable in a single period, and there is no carry-forward or carry-back of losses, all of which exaggerates the risk of the deductions. As presented, the model does not allow for risky inflation, the effect of which would depend on the systematic risk of nominally risk free claims. In spite of all this, the model should be a step in the direction of more realism, while retaining the possibility of an analytical solution.

\section{Conclusion}

Lund (2002a) showed that even in a fully equity financed firm, the beta of equity is decreasing in the tax rate under a typical corporate income tax. The main intuition was that a tax depreciation schedule acts risk-wise in the opposite direction of leverage: It is similar to a loan from the firm to the authorities. In light of this it has been important to consider a more realistic model for the uncertainty of the firm's tax position. The effect of a corporate income tax system on the systematic risk of equity after tax depends critically on loss offset provisions and the probability that the firm will be in tax position in future 
periods. This will depend on the total activities of a firm. This has been modelled as a decreasing-returns-to-scale technology, which has been acquired at an equilibrium entry cost, so that the total net value of the activity is zero. The model is a stylized quantification of the claim in, e.g., Gordon and Wilson (1986) and Summers (1987) that the tax value of deductions is close to risk free.

When the entry cost and the subsequent investment cost are treated differently by the tax system, there is a difference between the average and marginal beta of a project. The average beta will be reflected (if the model is true) in the stock market data for the firm's stock, while the marginal beta is relevant for each investment decision within the project. If required rates of return are to be derived from market data, this distinction has to be recognized.

When the firm is not certain to be in tax position at the margin in the future period, the valuation is similar to option valuation. Numerical techniques were used to solve for the systematic risk of equity in these cases. Even in this case the systematic risk of equity is less than the underlying systematic risk (relevant for a no-tax situation), it is decreasing in the tax rate, and increasing in the underlying volatility.

The methods and results demonstrated are crucial for discussions on reforms of corporate income taxation. In particular, the results on after-tax required returns are at odds with current practices. Only if the authorities and firms (and other participants) agree on these methods can there be meaningful discussions. In particular, if firms continue to rely on using required expected rates of return after tax which are fixed irrespective of taxes, there may be beneficial reforms which look bad in the eyes of these firms, cf. Lund (2002b).

\section{Acknowledgments}

This is a revised version of Lund (2003b). Most of the paper was written while the author was visiting the Department of Economics at Copenhagen Business School, Denmark. He is grateful for their hospitality and for comments during presentations, there and at EPRU/Copenhagen University, at IIPF 2003 in Prague, EFMA 2004 in Basel. 


\section{Appendix}

\section{Derivation of equations (18)-(22)}

This derivation starts with the average beta in case $R$. In case $R$ the cash flow to equity in period 1 is

$$
X_{R D}=P f(I)-t \cdot \max (P f(I)-c I, 0) .
$$

Under Assumption 6 the valuation, as of one period earlier, of a claim to this is

$$
\varphi\left(X_{R D}\right)=\varphi(P) f(I)-t\left[\varphi(P) f(I) N\left(z_{1 D}\right)-\frac{c I}{1+r} N\left(z_{2 D}\right)\right]
$$

where

$$
z_{1 D}=\frac{\ln (\varphi(P) f(I))-\ln \left(\frac{c I}{1+r}\right)}{\sigma}+\frac{\sigma}{2},
$$

and

$$
z_{2 D}=z_{1 D}-\sigma
$$

The expression in square brackets in (A2) can be rewritten in terms of the standard Black and Scholes' formula for option pricing as $C(\varphi(P) f(I), c I, 1, r, \sigma)$, so that

$$
\varphi\left(X_{R D}\right)=\varphi(P) f(I)-t C(\varphi(P) f(I), c I, 1, r, \sigma) .
$$

The $C$ function has derivatives $\partial C / \partial(\varphi(P) f(I))=N\left(z_{1 D}\right)$ and $\partial C / \partial(c I)=-N\left(z_{2 D}\right) /(1+$ $r)$, to be used below. ${ }^{17}$

The firm chooses $I$ to maximize $\pi_{R D}(I) \equiv \varphi\left(X_{R D}\right)-I(1-t a)$. The first-order condition is

$$
\varphi(P) f^{\prime}(I)=\frac{\left(1-t a-t N\left(z_{2 D}\right) \frac{c}{1+r}\right)}{\left(1-t N\left(z_{1 D}\right)\right)} .
$$

Introducing the constant-elasticity production function gives

$$
\varphi(P) f(I)\left(1-t N\left(z_{1 D}\right)\right)=\frac{I}{\alpha}\left(1-t a-t N\left(z_{2 D}\right) \frac{c}{1+r}\right) .
$$

Again, $M$ has an equilibrium value equal to $\pi_{R D}$, so that the total outlay for a firm to obtain the claim to the cash flow $X_{R D}$ is $M+I(1-t a)=\pi_{R D}+I(1-t a)=\varphi\left(X_{R D}\right)$. The claim is equivalent to holding a portfolio with $f(I)\left(1-t N\left(z_{1 D}\right)\right)$ claims on $P$, and the rest risk free. The beta is a value-weighted average of the betas of these two elements, i.e.,

$$
\beta_{R A}=\frac{\varphi(P) f(I)\left(1-t N\left(z_{1 D}\right)\right)}{\varphi\left(X_{R D}\right)} \beta_{P} .
$$


Here, the subscript $R A$ is introduced to show that this is the average beta in case $\mathrm{R}$. By introducing the expression for $\varphi\left(X_{R D}\right)$ from (A2) and the constant-elasticity production function, this can be simplified as

$$
\beta_{R A}=\frac{1-t a-t N\left(z_{2 D}\right) \frac{c}{1+r}}{1-t a-t N\left(z_{2 D}\right) \frac{c}{1+r}(1-\alpha)} \beta_{P} .
$$

It is also possible to express $z_{1 D}$ and $z_{2 D}$ in terms of exogenous variables, including the elasticity $\alpha$, avoiding the decision variables of the firm. Plug in from the first-order condition (A7) into (A3)-(A4) to find equation (19) in the main text.

In order to derive the marginal beta for the same case, consider first the marginal beta derived in Lund (2002a) for the case with an uncertain tax position, equation (24) in that paper. That paper's equation (23) becomes

$$
\gamma=\frac{1-t a-t N\left(z_{2 C}\right) \frac{c}{1+r}}{1-t N\left(z_{1 C}\right)}
$$

and the marginal beta can be written

$$
\beta_{R C}=\left(1-t a-t N\left(z_{2 C}\right) \frac{c}{1+r}\right) \beta_{P}
$$

The subscript $R C$ (C for CRS) is used here since the case considered in Lund (2002a) did not include the marginal project with some other activity, i.e., as if the case had constant returns to scale.

Again it is possible to express $z_{2 C}$ in terms of the exogenous parameters. In this case there is no first-order condition for an interior profit maximum, but the definition of a marginal CRS project, which gives

$$
\frac{\varphi(P) Q}{I}=\frac{1-t a-t N\left(z_{2 C}\right) \frac{c}{1+r}}{1-t N\left(z_{1 C}\right)},
$$

cf. equations (5) and (23) in Lund (2002a). This leads to equation (21) in the main text.

What then about the marginal beta for the DRS case? This can be seen as a mixture of the two cases just considered. The marginal beta characterizes a small investment which has a net value of zero. Under imperfect loss offset the value will depend upon the probability of being in tax position. In particular this is crucial in case $\mathrm{R}$, for which it is assumed that after period one there are no more periods, so that the loss cannot be 
carried forward (nor backward). The criterion for the project being marginal looks similar to (A12), but in this case the valuation of the option-like cash flow to the marginal project in period 1 is based on the risk-adjusted probabilities $N\left(z_{1 D}\right)$ and $N\left(z_{2 D}\right)$, not $N\left(z_{1 C}\right)$ and $N\left(z_{2 C}\right)$, since they should now reflect the probabilities that the whole DRS project is in tax position at the margin. The project which invests $I$ to yield $Q$, and which is taxed together with the optimally scaled DRS project, is marginal when

$$
\frac{\varphi(P) Q}{I}=\frac{1-t a-t N\left(z_{2 D}\right) \frac{c}{1+r}}{1-t N\left(z_{1 D}\right)} .
$$

The marginal beta in the DRS case becomes

$$
\beta_{R M}=\frac{1-t a-t N\left(z_{2 D}\right) \frac{c}{1+r}}{1-t a} \beta_{P},
$$

with $z_{2 D}$ given from (19) in the main text.

\section{Partial derivatives of $\beta_{R A}$}

This section considers the partial derivatives of $\beta_{R A}$ with respect to the parameters $t, c /(1+$ $r), \sigma$, and $\alpha$, and determines the signs of these for broad ranges of values of the parameters. However, in order to restrict the discussion, it will be assumed (a bit further below) that $a=0$. To simplify the notation, define $\hat{c} \equiv c /(1+r)$, and in this section write $z$ for $z_{2 D}$ defined in (19).

Implicit differentiation of that equation gives

$$
\begin{aligned}
\frac{\partial z}{\partial \sigma} & =\frac{1}{\sigma}\left[\frac{-t \hat{c} n(z) \frac{\partial z}{\partial \sigma}}{1-t a-t \hat{c} N(z)}+\frac{\operatorname{tn}(z+\sigma)\left(\frac{\partial z}{\partial \sigma}+1\right)}{1-t N(z+\sigma)}\right] \\
& -\frac{1}{\sigma^{2}}[\ln (1-t a-t \hat{c} N(z))-\ln (1-t N(z+\sigma))-\ln (\hat{c})-\ln (\alpha)]-\frac{1}{2}
\end{aligned}
$$

where $n(\cdot)$ denotes the standard normal density function.

This can be solved for

$$
\frac{\partial z}{\partial \sigma}=\frac{-(z+\sigma)+\frac{t n(z+\sigma)}{1-t N(z+\sigma)}}{\sigma+t\left[\frac{\hat{c} n(z)}{1-t a-t \hat{c} N(z)}-\frac{n(z+\sigma)}{1-t N(z+\sigma)}\right]} .
$$

Although difficult to prove analytically, it seems that the numerator is negative, while the denominator is positive. This has been verified numerically for $a=0$ and $\hat{c}=1 / 1.05$, 
considering a grid of $800(\alpha, \sigma, t)$ vectors, covering the reasonable ranges $\alpha \in[0.1,1], t \in$ $[0,0.7], \sigma \in[0.05,0.5]$. On this basis it is concluded that $\partial z / \partial \sigma<0$ for reasonable parameter values. The sign of the denominator is also needed below for the sign of the remaining partial derivatives. As verified numerically, it is assumed to be positive:

Assumption 8: There is no immediate tax relief for investment, i.e., $a=0$. Moreover,

$$
\sigma+t\left[\frac{\hat{c} n(z)}{1-t a-t \hat{c} N(z)}-\frac{n(z+\sigma)}{1-t N(z+\sigma)}\right]>0 \text {. }
$$

Consider now the partial derivative with respect to $\alpha$. Using the same method as above, we can show that

$$
\frac{\partial z}{\partial \alpha}=\frac{-(1 / \alpha)}{\sigma+t\left[\frac{\hat{c} n(z)}{1-t a-t \hat{c} N(z)}-\frac{n(z+\sigma)}{1-t N(z+\sigma)}\right]},
$$

which is negative under Assumption 8.

Furthermore, we find

$$
\frac{\partial z}{\partial t}=\frac{-\frac{a+\hat{c} N(z)}{1-t(a+\hat{c} N(z))}+\frac{N(z+\sigma)}{1-t N(z+\sigma)}}{\sigma+t\left[\frac{\hat{c} n(z)}{1-t a-t \hat{c} N(z)}-\frac{n(z+\sigma)}{1-t N(z+\sigma)}\right]} .
$$

It can be shown that the sign of the numerator is positive if and only if

$$
N(z+\sigma)-a-\hat{c} N(z)>0
$$

This restriction is implied by Assumption 7, but is somewhat weaker, since $N(z+\sigma)>$ $N(z)$. Under Assumption 7 (or the weaker restriction (A20)) and Assumption 8, we find $\partial z / \partial t>0$.

Next, we have

$$
\frac{\partial z}{\partial a}=\frac{-\frac{t}{1-t(a+\hat{c} N(z))}}{\sigma+t\left[\frac{\hat{c} n(z)}{1-t a-t \hat{c} N(z)}-\frac{n(z+\sigma)}{1-t N(z+\sigma)}\right]},
$$

which has the same sign as $\partial z / \partial \sigma$ and $\partial z / \partial \alpha$, negative under Assumption 8. The same is true for

$$
\frac{\partial z}{\partial \hat{c}}=\frac{-\frac{t N(z)}{1-t(a+\hat{c} N(z))}-\frac{1}{\hat{c}}}{\sigma+t\left[\frac{\hat{c} n(z)}{1-t a-t \hat{c} N(z)}-\frac{n(z+\sigma)}{1-t N(z+\sigma)}\right]},
$$

which has an additional term compared with $\partial z / \partial a$, since a higher $c$ affects the probability of being in tax position directly, not only via the optimal investment behavior. 
Consider now the partial derivatives of $\beta_{R A}$ from (A9). Let the denominator in (A9) be $D \equiv 1-t \hat{c} N(z)(1-\alpha)$. Then we find

$$
\frac{\partial \beta_{R A}}{\partial t}=\frac{\alpha \hat{c}}{D^{2}}\left[-\operatorname{tn}(z) \frac{\partial z}{\partial t}-N(z)\right] \beta_{P}
$$

which is negative under Assumption 8.

Next, we get

$$
\frac{\partial \beta_{R A}}{\partial \alpha}=\frac{-t \hat{c}}{D^{2}}\left[\alpha n(z) \frac{\partial z}{\partial \alpha}+(1-t \hat{c} N(z)) N(z)\right] \beta_{P}
$$

The sign of this is indeterminate: The expression in square bracket contains two terms of which the first is negative, while the second is positive. As a rough approximation, $(\partial z / \partial \alpha) \cdot \alpha \approx-(1 / \sigma)$, so that (since $n(z)<0.4)$ the positive term may dominate if $\sigma$ is sufficiently large, making the whole equation negative. The numerical illustration in Figures $1-5$ shows that the sign of this derivative changes from negative to positive as $\alpha$ increases. However, it can be shown that this does not have to happen when $\sigma$ is sufficiently large, in which case $\beta_{R A}$ becomes everywhere decreasing in $\alpha$.

Next, we find

$$
\frac{\partial \beta_{R A}}{\partial \sigma}=\frac{-\alpha t \hat{c} n(z)}{D^{2}} \cdot \frac{\partial z}{\partial \sigma} \beta_{P}
$$

which is positive under Assumption 8.

Finally, there is

$$
\frac{\partial \beta_{R A}}{\partial c}=\frac{-t \alpha}{D^{2}}\left[\hat{c} n(z) \frac{\partial z}{\partial c}+N(z)\right] \beta_{P}
$$

which has an indeterminate sign, even under Assumption 8. If $\sigma$ is not too small, the term containing $N(z)$ will dominate, making the derivative negative.

\section{Partial derivatives of before-tax cost of capital}

The cost of capital before taxes in the no-borrowing cases is the exogenous $E(P) / \varphi(P)$ multiplied by

$$
\gamma(t, a, \hat{c}, \sigma, \alpha) \equiv \frac{1-t a-t \hat{c} N(z)}{1-t N(z+\sigma)}
$$

given as expression (25) in the main text. As in the previous section of this appendix, the notation is simplified by writing $\hat{c}$ for $c /(1+r)$ and $z$ for $z_{2 D}$ defined in (19). Although not 
shown in the above equation, $z$ is itself a function of the same five variables, with partial derivatives given in equations (A17)-(A22). Case F with risk free deductions is obtained by letting both $N(\cdot)$ expressions equal to unity, and the CRS case is obtained when $\alpha \rightarrow 1$.

It would be interesting to determine the signs of the partial derivatives of this $\gamma$ function. The simplest expression is found for $\partial \gamma / \partial \alpha$, since $\alpha$ only has an effect via $z$. At first glance it may seem clear that a higher $\alpha$ leads to a lower $z$, thus a lower $N(z)$ and a lower $N(z+\sigma)$, which works just as a lower tax rate, reducing $\gamma$. But the facts that the arguments of the two $N(\cdot)$ expressions are different, and that $N$ is concave for positive argument values, imply that the reduction in $N(z)$ may exceed the reduction in $N(z+\sigma)$ sufficiently to lead to the opposite effect: It may happen that the reduction in the expected present tax value of the depreciation deduction has the higher impact, not the reduction in the conditional expected present value of the marginal tax rate on the revenue side.

Analytically: The derivative is

$$
\frac{\partial \gamma}{\partial \alpha}=\frac{[1-t N(z+\sigma)]\left(-t \hat{c} n(z) \frac{\partial z}{\partial \alpha}\right)+[1-t a-t \hat{c} N(z)] \operatorname{tn}(z+\sigma) \frac{\partial z}{\partial \alpha}}{(1-t N(z+\sigma))^{2}}
$$

The numerator can be written as

$$
t \frac{\partial z}{\partial \alpha}\{[1-t a-t \hat{c} N(z)] n(z+\sigma)-\hat{c}[1-t N(z+\sigma)] n(z)\}
$$

Even when $a=0$ it seems impossible to determine the sign of this expression analytically. While the first expression in square brackets is greater than $\hat{c}$ multiplied by the second, we will have $n(z+\sigma)<n(z)$ as long as $z>-\sigma / 2$.

A numerical investigation for $a=0, \hat{c}=1 / 1.05$, and the reasonable intervals $\alpha \in$ $[0.1,1], t \in[0,0.7], \sigma \in[0.05,0.5]$, shows that $\partial \gamma / \partial \alpha>0$ everywhere (on a grid of 800 points), while $\partial z / \partial \alpha<0$ (meaning that Assumption 8 is satisfied). This means that the expression in curly braces is negative, due to $n(z+\sigma)<n(z)$.

The economic interpretation is that even though a higher $\alpha$ lowers the probability of being in tax position, also when we take the optimal adjustment in $I$ into consideration, this does not correspond to a uniformly reduced tax rate. The impact on the marginal tax rate on deductions exceeds that on the marginal tax rate on revenue, which implies that the cost of capital is actually increased. 
The difficulty of determining the sign of $\partial z / \partial \alpha$ analytically carries over to the other four first-order partial derivatives, since the expression in curly braces reappears in all of them. Let $\Gamma$ be the expression in curly braces in (A29), and remember that a numerical investigation has shown that it is negative for the reasonable parameter values which were applied. The partial derivatives are fractions with a positive denominator, as in (A28), so we concentrate on the numerators. In connection with equations (A17)-(A22) it was concluded under Assumption 8 that $\partial z / \partial \sigma<0, \partial z / \partial t>0$ (under Assumption 7), $\partial z / \partial a<0$, and $\partial z / \partial \hat{c}<0$.

The numerator of $\partial \gamma / \partial \sigma$ is

$$
t \frac{\partial z}{\partial \sigma} \Gamma+[1-t a-t \hat{c} N(z)] \operatorname{tn}(z+\sigma)
$$

From the discussions above it is reasonable to assume that the first term is positive, and the same clearly holds for the second. The whole expression is thus positive.

The numerator of $\partial \gamma / \partial t$ is

$$
t \frac{\partial z}{\partial t} \Gamma+[N(z+\sigma)-a-\hat{c} N(z)]
$$

The first term is negative, cf. above. The second is positive (under Assumption 7), so the sign of the total effect is difficult to determine analytically. The numerical investigation showed that $\partial \gamma / \partial t>0$ everywhere on the grid.

The numerator of $\partial \gamma / \partial a$ is

$$
t \frac{\partial z}{\partial a} \Gamma-t[1-t N(z+\sigma)]
$$

The first term is positive, cf. above. The second term, including its minus sign, is negative, so the sign of the total is indeterminate.

The numerator of $\partial \gamma / \partial \hat{c}$ is

$$
t \frac{\partial z}{\partial \hat{c}} \Gamma-t N(z)[1-t N(z+\sigma)]
$$

The first term is positive, cf. above. The second term, including its minus sign, is negative, so the sign of the total cannot be determined analytically. The numerical investigation showed that $\partial \gamma / \partial \hat{c}<0$ everywhere on the grid. 
For the parameter ranges investigated, the indirect effects of $t$ and $\hat{c}$ on $\gamma$ via changes in $z$ counteract the direct effects found from the case of risk free deductions, cf. (24). But the indirect effects are of second order importance, and cannot overturn the direct effects. 


\section{Notes}

${ }^{1}$ See, e.g., Brealey and Myers (2003), section 19.3.

${ }^{2}$ The present paper extends Lund (2002a). Lund (2003a) uses a different set of assumptions, more general in some respects, more specialized in others. One main difference is that Lund (2003a) does not specify a CAPM relationship, only a more general model with value additivity, like in Modigliani and Miller (1963). It is also more general in that it does not assume multiplicative uncertainty, $P Q$ with $Q$ deterministic, as do Lund (2002a) and the present paper. On the other hand, Lund (2003a) relies on very specific multi-period profiles for production, depreciation and borrowing, and does not allow for uncertainty in tax positions or decreasing returns to scale. An appendix in Lund (2003b) shows the exact relationship between the models of the present paper and Lund (2002a) on the one hand, and those of Lund (2003a) on the other.

${ }^{3}$ The divergence between the results of Derrig (1994) and of the present paper is spelt out in Lund (2001).

${ }^{4}$ Lund (2002a) has a multiperiod extension for the case with a risk free tax position.

${ }^{5}$ Of course, $r_{i}$ is the rate of return of shares in firm $i, r$ may be thought of as the riskless interest rate (but see footnote 7 ), $r_{m}$ is the rate of return on the market portfolio, $\beta_{i} \equiv \operatorname{cov}\left(r_{i}, r_{m}\right) / \operatorname{var}\left(r_{m}\right)$, and $E$ is the expectation operator. The original model is derived in Sharpe (1964), Lintner (1965), and Mossin (1966).

All variables are nominal. As long as the tax system is based on nominal values, the model is only consistent with a rate of inflation which is known with certainty, and fixed exchange rates. The underlying real CAPM would then be

$$
\frac{1+E\left(r_{i}\right)}{1+\dot{p}}=\frac{1+r}{1+\dot{p}}+\beta_{i}\left[\frac{1+E\left(r_{m}\right)}{1+\dot{p}}-\frac{1+r}{1+\dot{p}}\right]
$$

where $\dot{p}$ is the rate of inflation. 
${ }^{6}$ In Bulow and Summers (1984) it is assumed that even a change in the U.S. corporate tax system can be meaningfully analyzed with partial equilibrium methods, since the firms traded in the U.S. capital market have their activities world wide, and the "U.S. corporate sector represents less than one-tenth of the world free market wealth" (their footnote 3 ).

${ }^{7}$ In fact $r$ could be the riskless interest rate multiplied by a factor $\theta$ which corrects for differences in the tax treatment on the hands of the firm's owners of income from equity and income from riskless bonds, reflected in the tax parameter $\theta$. This is included in Lund (2002a). A tax-adjusted CAPM appears, e.g., in Sick (1990) or Benninga and Sarig (2003). In a discussion of taxation and the CAPM it seems reasonable to allow for $\theta<1$, but it has no consequences for the results which follow. The standard CAPM with $\theta=1$ is all that is needed. In the present paper there is no borrowing, so the riskless rate has no separate significance apart from its appearance in the CAPM equation. Thus $r$ is simply defined as the intercept in the CAPM equation. Lund (2002a) allows riskless debt and $\theta<1$.

${ }^{8}$ The product price has what McDonald and Siegel (1984) call an (expected-)rate-ofreturn shortfall.

${ }^{9}$ In parts of the literature, such as King (1977), p. 232, the nominal sum of deductions, here $a+c$, is set to unity. But there "is not need to restrict the sum" of deductions "to unity," according to King and Fullerton (1984), p. 19, who observe that at "certain times it exceeds unity (for example, when accelerated depreciation does not reduce the base for standard depreciation allowances)." In the present paper, $a$ and $c$ are considered as separate, exogenous variables, so that an increase in $a$ is analyzed as if $c$ is kept constant, and vice versa.

${ }^{10}$ It would certainly be interesting to consider leverage and uncertain tax positions in the same model. However, the analysis which follows, and in particular the extension to more general tax deductions in the appendix, is sufficiently complicated as it is. After all, it is well known that the beta of equity depends on the tax rate in the presence of leverage, and one main point of Lund (2002a) and the present paper is to establish that this also holds in the absence of leverage. Two starting points for extending this research to 
combine leverage and an uncertain tax position are Galai (1988) with risky debt and Lund (2002a) with default-free debt. Assumptions 3 and 5 in Lund (2002a) may be somewhat unrealistic when taken together. They imply that the debt is repaid with certainty, for instance by a parent company if the firm analyzed has insufficient cash flow. At the same time the tax value of the interest deduction is only obtained to the extent that the firm is in tax position. One could imagine instead that the parent company also obtains an interest deduction, but perhaps at a different tax rate.

${ }^{11}$ The present paper improves upon the solution for the case considered in Lund (2002a), by pointing out that the variables $z_{1}$ and $z_{2}$, called $x_{1}$ and $x_{2}$ in equation (19) in that paper, can be rewritten in terms of the exogenous parameters, given that the production function has a constant elasticity. Observe in particular that whereas the option value in general depends on a rate-of-return shortfall (in an unconstrained equilibrium often identified as a convenience yield), this dependency disappears here, given that the first-order condition of the firm is satisfied.

${ }^{12}$ Specifically, additive noise could be $\varepsilon$, stochastically independent of $\left(P, r_{m}\right)$, with $E(\varepsilon)=0$. Then $\operatorname{cov}\left(P+\varepsilon, r_{m}\right)=\operatorname{cov}\left(P, r_{m}\right)$. Multiplicative noise could be $\psi$, stochastically independent of $\left(P, r_{m}\right)$, with $E(\psi)=1$. Then $\operatorname{cov}\left(P \psi, r_{m}\right)=\operatorname{cov}\left(P, r_{m}\right)$. These reasonable cases show that the correlation coefficient of $\left(P, r_{m}\right)$ should not (always) be assumed unaffected if $P$ becomes more risky. This points out an important reservation to the discussion in Dixit and Pindyck (1994), in particular the claim on p. 179 that "when the $\sigma$ of the $P$ asset increases, $\mu$ must increase" (where $\mu$ is the required expected rate of return according to the CAPM). This is not true in general (but it can be true due to non-linear taxation). Of course, the argument made here does not mean that $\sigma$ could be zero while $\beta$ is different from zero. See also the discussion in section 4 of Lund (2005).

${ }^{13}$ The solutions (when $a=0$ and $\left.c /(1+r)=1 / 1.05\right)$ show that $z_{2 D}$ is negative approximately when $\sigma-t-2(1-\alpha) \geq 0.3$, an (approximate) linear relationship. To interpret this, recall that $N\left(z_{2 D}\right)$ is the risk-adjusted probability of being in tax position. This will be less than 0.5 if $\sigma$ and $\alpha$ are large, while $t$ is small. Since the formula relies on the first order condition, the effect via optimal investment is included here. Optimal investment increases 
when $t$ is small, even though this increases the probability of being out of tax position at the margin. A high $\alpha$ reduces the infra-marginal profit. The effect of an increased $\sigma$ may not be so obvious, since the probability of $P$ being less than its median is unaffected (and equal to 0.5 ). But the tax base also includes a negative constant term, which explains the effect.

${ }^{14}$ For each numerical version of each of the nonlinear equation systems (19) and (21) the solution method identified one solution which might not be a unique solution. The program then did a grid search through 400 values of $z_{2}$ for other solutions, but these were never found. It seems reasonable to conclude that the solutions found are likely to be unique. For equation (21) the uniqueness may depend on $\alpha$ being a constant. A more general version with a non-constant $\alpha(I)$ might lead to several solutions.

${ }^{15}$ So far no indications have been found that the dependency on $t$ or $\sigma$ should be nonmonotonous. But these are solutions to non-linear equations, and the possibility has not been ruled out. For the parameters shown, however, there is every reason to believe that the solutions are unique.

${ }^{16}$ This effect of a different tax rate becomes particularly pronounced under some systems of taxation of natural resource rents, in which marginal tax rates on firms have been between 50 and 85 percent. When these systems have investment based deductions spread over several years, such as depreciation deductions, the beta of equity becomes quite low. Serious mistakes could be made if firms apply the same cost of equity under such tax systems as under others, cf. Lund (2002b).

${ }^{17}$ The partial derivatives of Black and Scholes' formula can be found, e.g., in Haug (1998), or in most textbooks on option theory. They look as if they neglect the dependence of $z_{1}$ and $z_{2}$ on the arguments, but they do not. 


\section{References}

Ball, R., Bowers, J., 1983. Distortions created by taxes which are options on value creation: The Australian Resource Rent Tax proposal. Australian Journal of Management 8, 114.

Benninga, S., Sarig, O., 2003. Risk, returns, and values in the presence of differential taxation. Journal of Banking and Finance 27, 1123-1138.

Bond, S.R., Devereux, M.P., 1995. On the design of a neutral business tax under uncertainty. Journal of Public Economics 58, 57-71.

Brealey, R.A., Myers, S.C., 2003. Principles of Corporate Finance, seventh ed. McGrawHill, Boston, Massachusetts.

Bulow, J.I., Summers, L.H., 1984. The taxation of risky assets. Journal of Political Economy 92, 20-39.

Derrig, R.A., 1994. Theoretical considerations of the effect of federal income taxes on investment income in property-liability ratemaking. Journal of Risk and Insurance 61, 691-709.

Dixit, A.K., Pindyck, R.S., 1994. Investment under Uncertainty. Princeton University Press, Princeton, New Jersey.

Fane, G., 1987. Neutral taxation under uncertainty. Journal of Public Economics 33, 95-105.

Galai, D., 1988. Corporate income taxes and the valuation of the claims on the corporation. Research in Finance 7, 75-90.

Gordon, R.H., Wilson, J.D., 1989. Measuring the efficiency cost of taxing risky capital income. American Economic Review 79, 427-439.

Graham, J.R., 1996. Proxies for the corporate marginal tax rate. Journal of Financial Economics 42, 187-221.

Graham, J.R., Harvey, C.R., 2001. The theory and practice of corporate finance: evidence from the field. Journal of Financial Economics 60, 187-243. 
Green, R.C., Talmor, E., 1985. The structure and incentive effects of corporate tax liabilities. Journal of Finance 40, 1095-1114.

Hall, R.E., Jorgenson, D.W., 1969. Tax policy and investment behavior: Reply and further results. American Economic Review 59, 388-401.

Haug, E.G., 1998. The Complete Guide to Option Pricing Formulas. McGraw-Hill, New York.

King, M.A., 1977. Public Policy and the Corporation. Chapman and Hall, London.

King, M.A., Fullerton, D., 1984. The Taxation of Income from Capital. University of Chicago Press, Chicago, Illinois.

Levy, H., Arditti, F.D., 1973. Valuation, leverage, and the cost of capital in the case of depreciable assets. Journal of Finance 28, 687-693.

Lintner, J., 1965. The valuation of risk assets and the selection of risky investments in stock portfolios and capital budgets. Review of Economics and Statistics 47, 13-27.

Lund, D., 2001. Taxation, uncertainty, and the cost of equity for a multinational firm. Memorandum no. 13/2001, Department of Economics, University of Oslo, Norway, http://folk.uio.no/dilund/capcost.

Lund, D., 2002a. Taxation, uncertainty, and the cost of equity. International Tax and Public Finance 9, 483-503.

Lund, D., 2002b. Petroleum tax reform proposals in Norway and Denmark. Energy Journal $23(4), 37-56$.

Lund, D., 2003a. Valuation, leverage and the cost of capital in the case of depreciable assets: Revisited. Working Paper 03-2003, Department of Economics, Copenhagen Business School, Denmark. Presented at the Midwest Finance Association's annual meeting in St. Louis, March 2003.

Lund, D., 2003b. Taxation and systematic risk under decreasing returns to scale. Working Paper 02-2003, Department of Economics, Copenhagen Business School, Denmark. Presented at the 59th annual congress of the International Institute of Public Finance in Prague, August 2003. 
Lund, D., 2005. How to analyze the investment-uncertainty relationship in real option models? Review of Financial Economics, forthcoming.

McDonald, R., Siegel, D., 1984. Option pricing when the underlying asset earns a belowequilibrium rate of return: A note. Journal of Finance 34, 261-265.

McDonald, R., Siegel, D., 1986. The value of waiting to invest. Quarterly Journal of Economics 101, 707-727.

Modigliani, F., Miller, M.H., 1963. Corporate income taxes and the cost of capital: A correction. American Economic Review 53, 433-443.

Mossin, J., 1966. Equilibrium in a capital asset market. Econometrica 35, 768-783.

Myers, S.C., 1974. Interactions of corporate financing decisions and investment decisions — implications for capital budgeting. Journal of Finance 24, 1-25.

Shanker, L., 2000. An innovative analysis of taxes and corporate hedging. Journal of Multinational Financial Management 10, 237-255.

Sharpe, W.F., 1964. Capital asset prices: A theory of market equilibrium under conditions of risk. Journal of Finance 19, 425-442.

Shevlin, T., 1990. Estimating corporate marginal tax rates with asymmetric tax treatment of gains and losses. Journal of the American Taxation Association 11, 51-67.

Sick, G.A., 1990. Tax-adjusted discount rates. Management Science 36, 1432-1450.

Summers, L.H., 1987. Investment incentives and the discounting of depreciation allowances. In: Feldstein, M. (Ed), The Effects of Taxation on Capital Accumulation. University of Chicago Press, Chicago, Illinois, pp. 295-304. 


\begin{tabular}{|c|c|c|c|c|c|}
\hline & $N\left(z_{2}\right)$ & $\alpha$ & $\begin{array}{l}\text { marginal } \\
\text { vs. average }\end{array}$ & $\beta_{i}$ & $\beta_{i} / \beta_{P}$ \\
\hline \multirow{2}{*}{$\begin{array}{c}\text { Case } \\
\text { F }\end{array}$} & \multirow{2}{*}{1} & 1 & marginal & $\beta_{F C}$ & $\frac{1-t a-t \frac{c}{1+r}}{1-t a}$ \\
\hline & & $\in(0,1)$ & average & $\beta_{F D}$ & $\frac{1-t a-t \frac{c}{1+r}}{1-t a-t \frac{c}{1+r}(1-\alpha)}$ \\
\hline \multirow{3}{*}{$\begin{array}{c}\text { Case } \\
\mathrm{R}\end{array}$} & \multirow{3}{*}{$\in(0,1)$} & 1 & marginal & $\beta_{R C}$ & $\frac{1-t a-t N\left(z_{2 C}\right) \frac{c}{1+r}}{1-t a}$ \\
\hline & & $\in(0,1)$ & marginal & $\beta_{R M}$ & $\frac{1-t a-t N\left(z_{2 D}\right) \frac{c}{1+r}}{1-t a}$ \\
\hline & & $\in(0,1)$ & average & $\beta_{R A}$ & $\frac{1-t a-t N\left(z_{2 D}\right) \frac{c}{1+r}}{1-t a-t N\left(z_{2 D}\right) \frac{c}{1+r}(1-\alpha)}$ \\
\hline
\end{tabular}

Equations implicitly defining $z_{2 C}$ and $z_{2 D}$ :

$$
\begin{aligned}
& z_{2 C}=\frac{1}{\sigma}\left[\ln \left(1-t a-t N\left(z_{2 C}\right) \frac{c}{1+r}\right)-\ln \left(1-t N\left(z_{2 C}+\sigma\right)\right)-\ln \left(\frac{c}{1+r}\right)\right]-\frac{\sigma}{2} \\
& z_{2 D}=\frac{1}{\sigma}\left[\ln \left(1-t a-t N\left(z_{2 D}\right) \frac{c}{1+r}\right)-\ln \left(1-t N\left(z_{2 D}+\sigma\right)\right)-\ln \left(\frac{c}{1+r}\right)-\ln (\alpha)\right]-\frac{\sigma}{2}
\end{aligned}
$$

Table 1: Beta of equity for the five subcases, divided by $\beta_{P}$ 


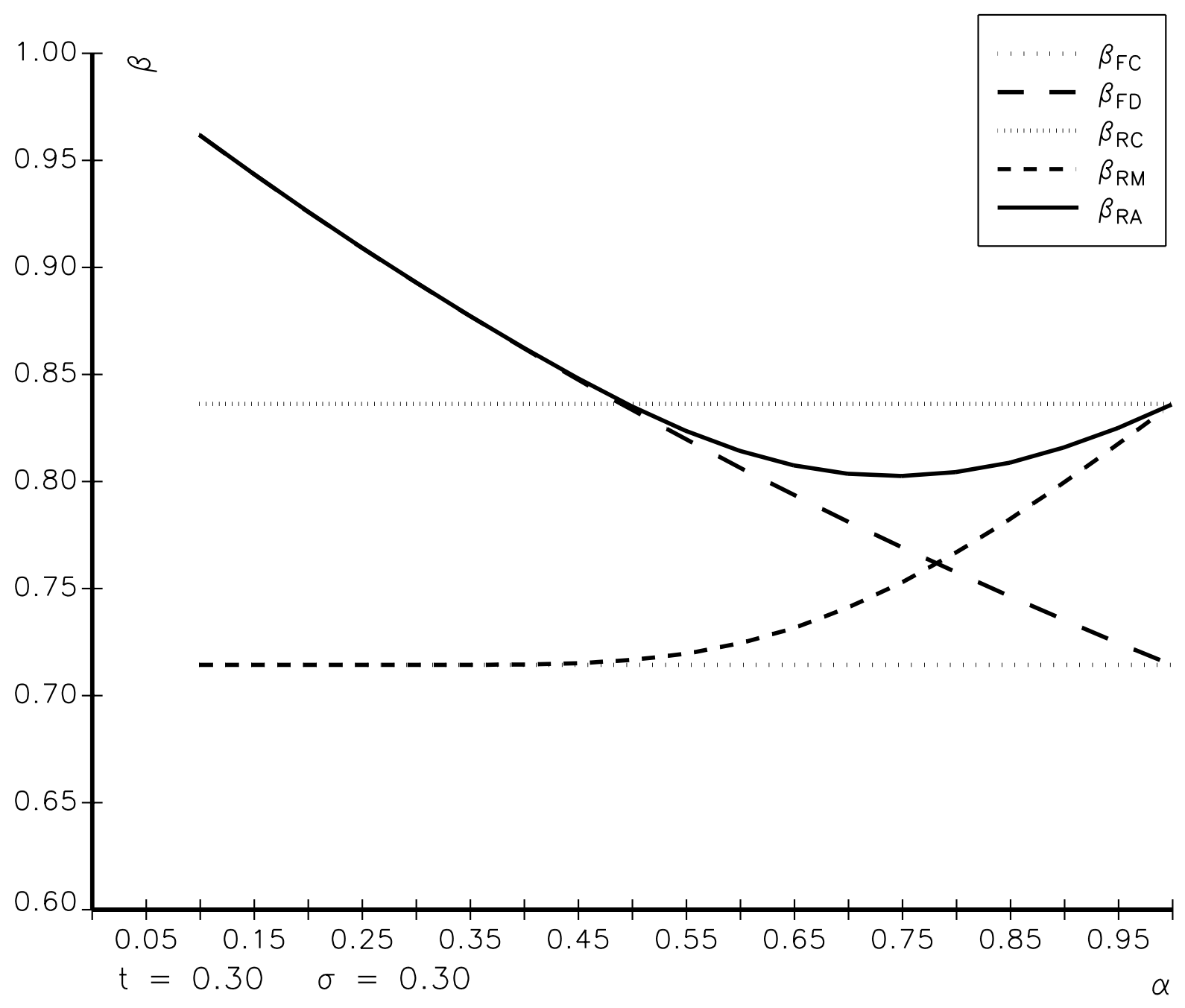

Figure 1: $\beta_{i} / \beta_{P}$ as functions of scale elasticity, $\alpha ; t=\sigma=0.3, c /(1+r)=1 / 1.05$ 


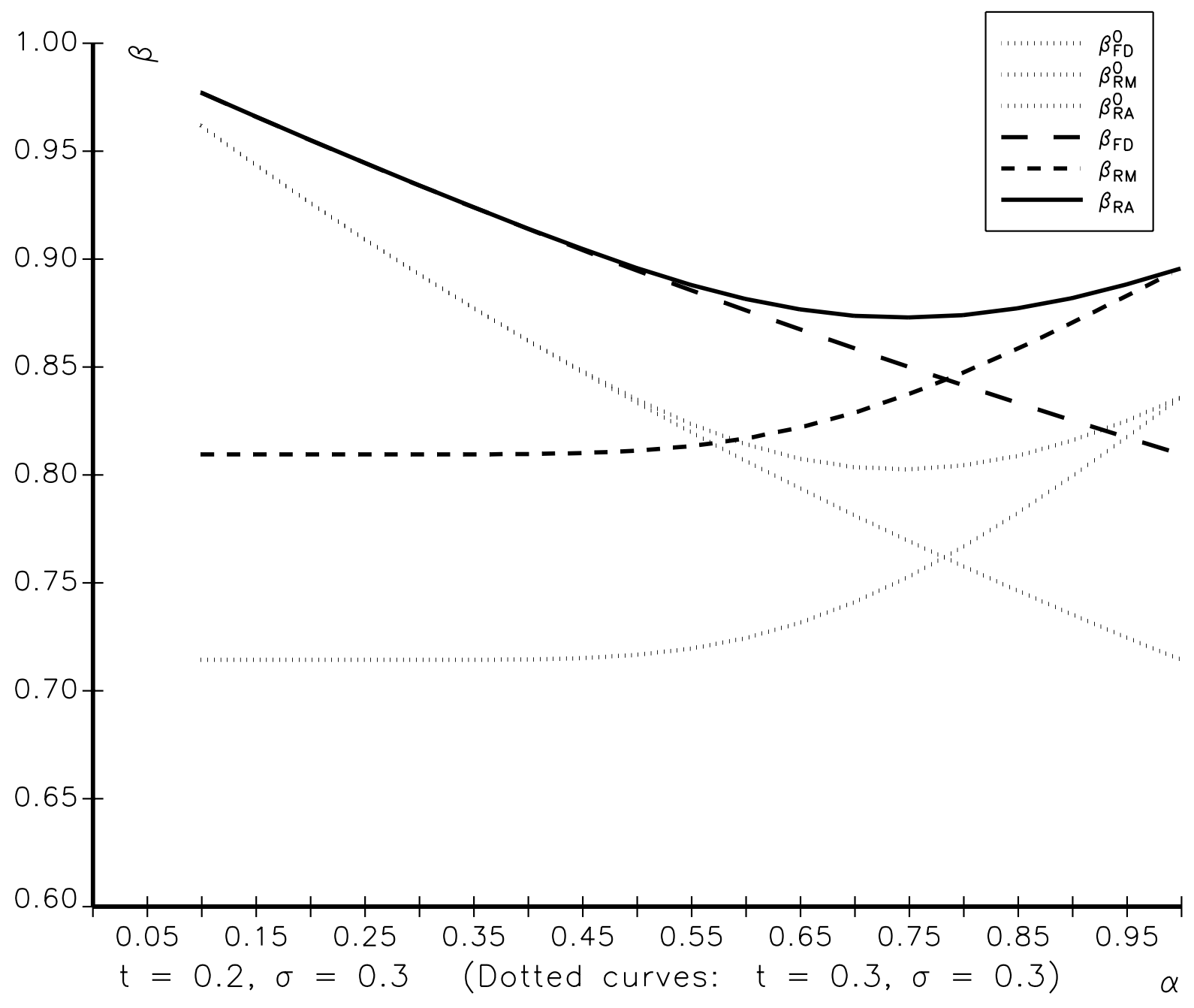

Figure 2: $\beta_{i} / \beta_{P}$ as functions of scale elasticity, $\alpha$; varying the tax rate 


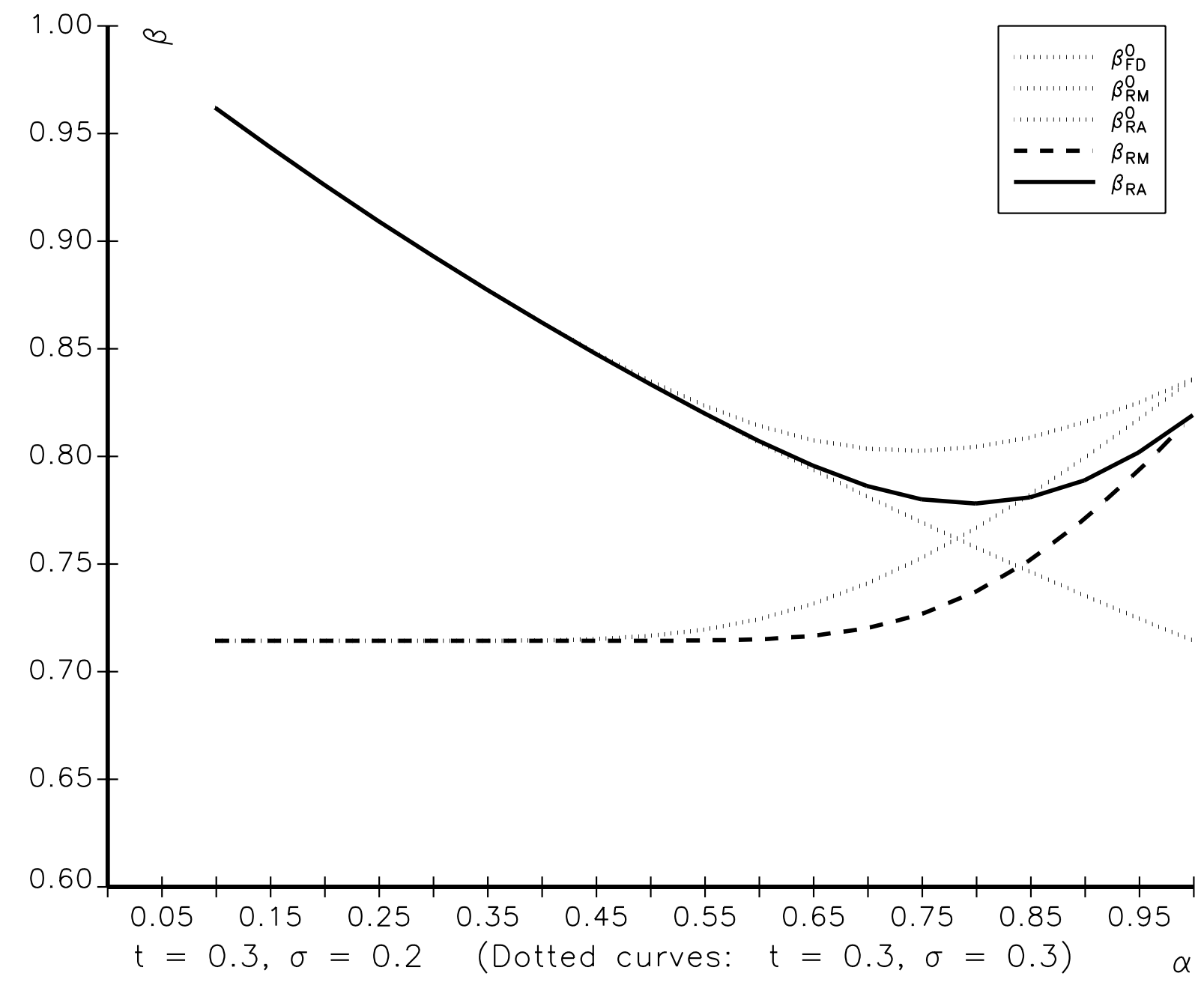

Figure 3: $\beta_{i} / \beta_{P}$ as functions of scale elasticity, $\alpha$; varying the volatility 